\title{
Oro-Facial Findings in Orthodontic Alagille Patient: First Documented Case Presenting Multiple Agenesis
}

\author{
Marco Farronato*, Pinadelia Bisconte, Guido Galbiati and Davide Farronato \\ Università degli Studi di Milano, Italy
}

*Corresponding author: Marco Farronato, Università degli Studi di Milano, Fondazione IRCCS Cà Granda -Ospedale Maggiore Policlinico, Via della commenda 10 CAP: 20122 Milano (MI) Italy

Submission: 眥 November 16, 2017; Published: 䟧 February 05, 2018

\begin{abstract}
Alagille syndrome (ALGS) is a complex multi-systemic genetic disorder which involves primarily the liver, heart, eyes, face, and skeletal structure. The purpose of the work is to report a case of Alagille syndrome in which the facial and dental characteristics of the patient were analyzed.

Methods: A clinical and radiographic examination of the 15-year-old patient was performed with orthopantomography of dental arches and teleradiography of the skull in lateral-lateral projection. A cephalometric trace was performed which presented 2 class values, deep bite.

Results: The case presents commons skeletal and dental findings of this syndrome reported in literature: maxillary hypoplasia, maxillo-mandibular retrusion, a class II molar relationship on both sides, a deep overbite, talon cusp on element 22. A further feature that this case presents is agenesis of elements 35 e 45 with infra occlusion of elements 75 and 85.
\end{abstract}

Conclusion: In clinical and radiographic analysis, the patient showed the common characteristics reported in the literature for Alagille's syndrome. In addition, a feature not reported in the literature for this syndrome, i.e. agenesis of elements 35 and 45 , has been found. These patients need orthodontic early diagnosis as they may present skeletal and dental characteristics that may be intercepted early second class, talon cusps and eventually agenesis.

Keywords: Alagille syndrome; Agenesis; Talon cusp; Premolar agenesis

\section{Introduction}

Alagille syndrome (AGS) was first described by David Alagille in 1975 as an autosomal dominant disease affecting multiple systems including the liver, heart, eyes, skeleton, and face [1]. AGS is most commonly caused by mutations or deletions of the gene encoding Jagged 1 (JAG1), a ligand involved in the Notch signaling pathway and it is a rare disease with an incidence of 1 in 100,000 live births. AGS is diagnosed if three or more of the following five major features are present: cardiac murmur, posterior embryotoxon, butterfly vertebrae, renal abnormalities, and characteristic facies, along with histological diagnosis of bile duct paucity [2].

The main features of the syndrome are: paucity of intrahepatic bile ducts with cholestasis, cardiac defects, posterior embryotoxon in the eyes, renal and central nervous system abnormalities, butterfly vertebrae [1]. Oro-facial manifestations can include: prominent forehead, moderate hypertelorism with deep-set eyes, a saddle or straight nose with a flattened, bulbous tip, large ears. Before the age of 1 , oro-facial characteristics are less recognizable but they can still help to an early diagnosis, in posterior development later the child's facies typically has a prominent forehead and delicate pointed chin, giving the face an inverted triangular appearance.
At about the time of puberty, the chin becomes more prominent, becoming prognathic, and there is less dominance of the forehead [3].

Depending on the state of the liver disorders, AGS may also damage teeth, salivary glands, periodontium, and mucous membranes. Dental manifestations are not a primary concern of the syndrome, but they invariably occur as a complication of the long-lasting cholestasis and are linked to hyper bilirubinemia [3]. As a consequence of cholestasis occurring during odontogenesis, enamel opacities, hypomineralization, and hypoplasia of tooth enamel can be found. In children with serum bilirubin level more than $30 \mathrm{mg} / \mathrm{dl}$, biliverdin accumulates in the dental tissues, causing a variable, greenish-brown dyschromia of teeth. The pigmentation can be modified by the hemal translucency that transmits the dentinal color. Both the primary and permanent dentition can be heavily affected if they develop before the resolution of jaundice. Authors report presence of talon cusps in primary and permanent teeth in patients with AGS. Different data show macrodontic maxillary incisor and, in a few cases, taurodontic deciduae teeth with a widened pulpal cavity [4]. Extensive decalcification of pre 
dentin and inter-globular dentin invariably occurs. Ho et al. noticed that patients with Alagille syndrome might present hypodontia and oral xanthomas [3].

In the case of patient presenting AGS and chronic liver disease, the food deficiency, lack of immunity, and coagulation disorders play an important role in their oral condition. Under nutrition and as a result, lack of proteins, vitamins A, D, K, E, group B vitamins, macro and microelements like iron, calcium, phosphorus, zinc, magnesium, cuprum, and manganese may manifest in their oral cavity in the dental and periodontal tissues, as well as oral mucosa [3]. Among children with chronic liver disease were also found delayed tooth eruption and dilated pulp chambers and radicular space, most likely due to vitamin D deficiency. Studies have shown that under nutrition can cause decreased saliva secretion and reduced level of proteins, immune globulins type A, amylase, and lysozyme. All these factors together increase the risk for caries formation. Poor hygiene predisposes to the development of gingivitis and paradontopathies [1-3].

Talon cusp is a rare dental anomaly often associated with systemic conditions such as Rubenstein-Taybi Syndrome, Ellis-van Crevald Syndrome and Incontentia pigmenti achromians [5]. It has been previously reported as occurring in Alagille Syndrome. Early diagnosis of talon cusps is crucial for the correct management and avoidance of Complications [6]. Contrary to healthy children, patients with Alagille syndrome have many problems to deal with during their development, so often the oro-facial complex could not be seen as a primary necessity: depending on several factors like the severity of cholestasis and scarring in the liver, heart or lung problems, presence of infections, or other problems related to poor nutrition that can manifest in their oral cavity in the dental and periodontal tissues, as well as oral mucosa [7]. From the odontostomatologic point of view, the most important elements are: careful observation, accurate diagnosis, and planned management of such patients, especially during the patient's formative years, to prevent complications [8]. Aggressive preventive oral care and consultations with medical specialists before any invasive procedure are strongly recommended. All of this can improve the quality of life in patients with Alagille syndrome [1,9-12].

\section{Case Report}

A 15-year-old female came to our visit with medical history of ALGS. The patient was in treatment with ursodeoxycholic acid as she presents perimembranous inter ventricular defect and bilateral articular restenosis. The genetic background of the patient shows a deletion of chromosome 20p en-compassing JAG1. Clinical examination revealed recognizable characteristics ALGS traits: broad forehead, deep-set eyes with eye-socket, maxillary hypoplasia, maxillo-mandibular retrusion (Figure $1 \& 2$ ). The patient presented molar class II on both sides, a normo-overjet and a $4 \mathrm{~mm}$ overbite (Figure 3). An intra-oral examination revealed presence of a talon cusp on the element 22 (Figure 4) infra-occlusion of the elements 75 and 85 (Figure 5). Panoramic radiograph showed a agenesis of the elements 35 and 45 . Also 180 degrees rotation of the element 15 was found (Figure 6). Her dental management so far has involved improving of oral hygiene and placing fissure sealant on the molars. Aggressive preventive oral care is a primary need in those patients. Dental development was normal for the patient's chronological age and there was no carious lesion. No previous publication reported AGS patient presenting single or multiple agenesis, since AGS is a rare syndrome more cases are needed to investigate to exclude any possible relationship.
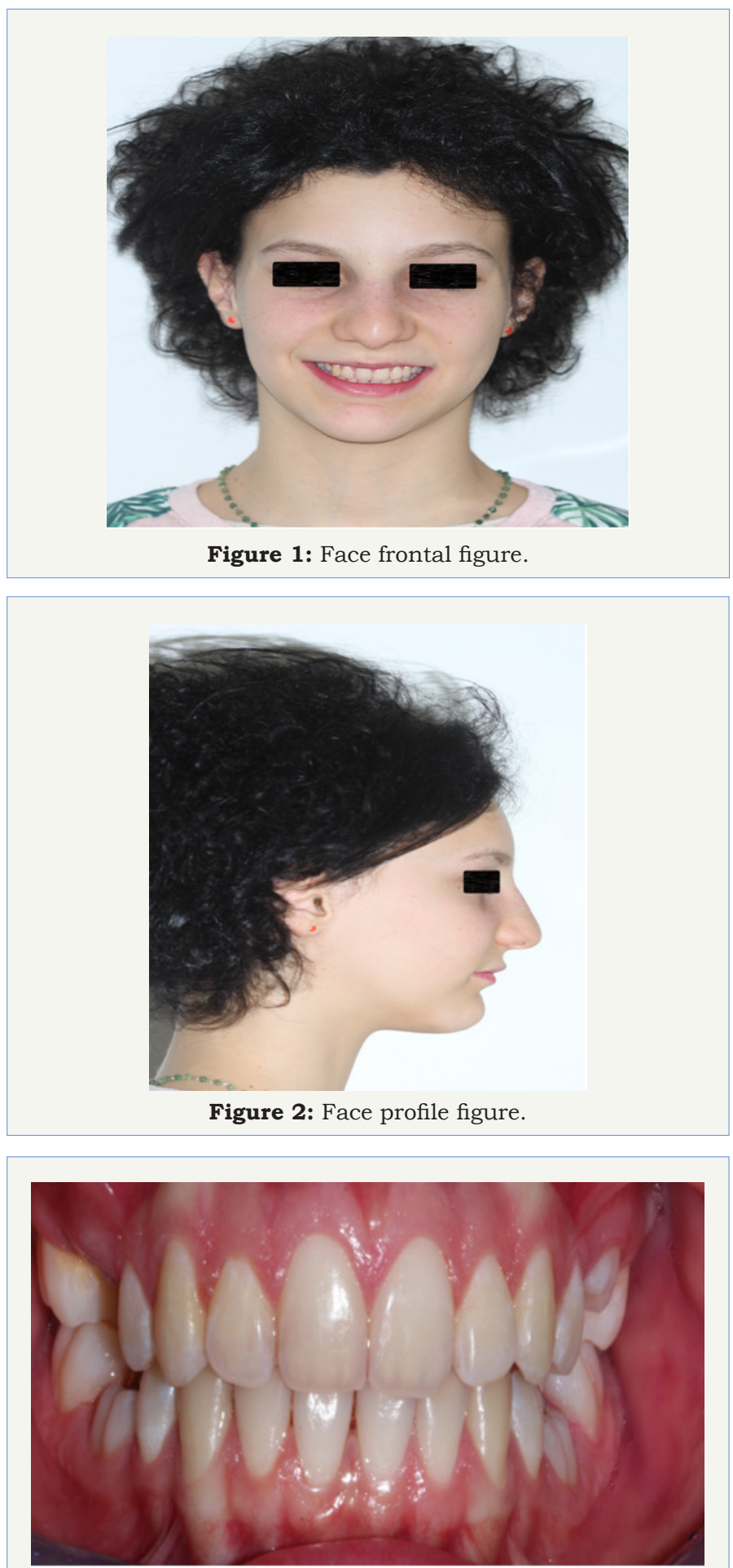

Figure 3: Intra-oral frontal figure. 


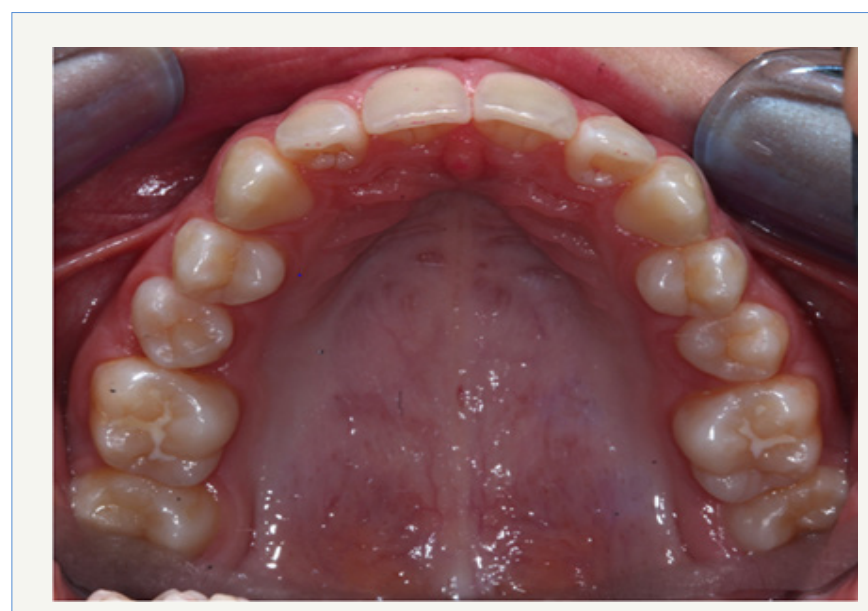

Figure 4: Upperdentalarch figure.
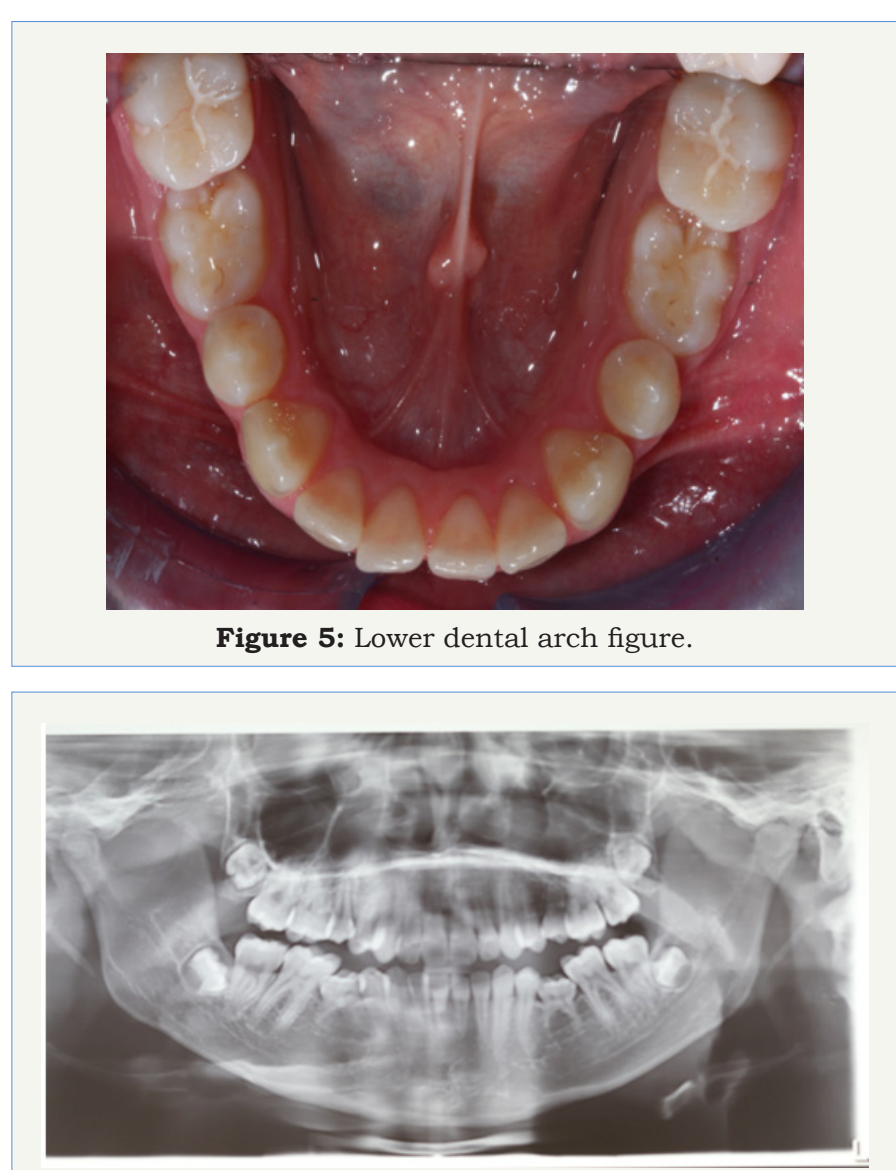

Figure 6: Orthopantomography.

Cephalometric analysis of the patient, according to the school of Milano, gives the following values (obtained with software Deltadent $($ ) (Table 1), these measurements show a skeletal class II with retrusion of maxilla (SNA $73,4^{\circ}$ ) and mandibula (SNB $\left.68,9^{\circ}\right)$. Also a significant retro-inclination of the upper incisors $\left(\mathrm{API}+\mathrm{INI}^{\wedge} \mathrm{S}-\mathrm{N} 84,7^{\circ}\right)$ [8].

\section{Discussion}

Many of the principal characteristics of Alagille syndrome reported in literature are found in this case. No previous literature case reports agenesis, so this might be the first case. Avoidance of deciduous impaction and ankylosis is a primary concern in patient in which medical condition could be unstable and bony tissues could suggest conservative treatment and the avoidance of complicate extractions and implant placement. The role of the dentist and of the orthodontic care must not be underestimated to avoid more complex medical complications especially those which require the use of anesthesia due to their medical condition [3-5].

Table 1: Cephalometric analisys according to the School of Milano

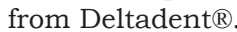

\begin{tabular}{|c|c|c|c|c|c|}
\hline Name & Val & Min & Med & Max & Diff \\
\hline \multicolumn{6}{|c|}{ Angular Values } \\
\hline SNA & $73,4^{\circ}$ & $80^{\circ}$ & $82^{\circ}$ & $84^{\circ}$ & $6,6^{\circ}$ \\
\hline SNB & $68,9^{\circ}$ & $78^{\circ}$ & $80^{\circ}$ & $82^{\circ}$ & $9,1^{\circ}$ \\
\hline ANB & $4,5^{\circ}$ & $0^{\circ}$ & $2^{\circ}$ & $4^{\circ}$ & $0,5^{\circ}$ \\
\hline Ar-Go-Gn & $130,5^{\circ}$ & $115^{\circ}$ & $120^{\circ}$ & $125^{\circ}$ & $5,5^{\circ}$ \\
\hline Ar-Go-N & $57,6^{\circ}$ & $48^{\circ}$ & $50^{\circ}$ & $52^{\circ}$ & $5,6^{\circ}$ \\
\hline N-Go-Gn & $72,9^{\circ}$ & $67^{\circ}$ & $70^{\circ}$ & $73^{\circ}$ & $0^{\circ}$ \\
\hline Cranio mandibular angle & $41,8^{\circ}$ & $27^{\circ}$ & $32^{\circ}$ & $37^{\circ}$ & $4,8^{\circ}$ \\
\hline Intermaxillar Angle & $37^{\circ}$ & $15^{\circ}$ & $20^{\circ}$ & $25^{\circ}$ & $12^{\circ}$ \\
\hline Cranio-Max Angle & $4,8^{\circ}$ & $7^{\circ}$ & $10^{\circ}$ & $13^{\circ}$ & $2,2^{\circ}$ \\
\hline $\begin{array}{l}\text { Inclination of upper } \\
\text { incisors API+INI^S-N }\end{array}$ & $84,7^{\circ}$ & $101^{\circ}$ & $103^{\circ}$ & $105^{\circ}$ & $16,3^{\circ}$ \\
\hline $\begin{array}{c}\text { Inclination of lower } \\
\text { incisors API-INI-^ } \mathrm{Go}-\mathrm{Gn}\end{array}$ & $96,9^{\circ}$ & $85^{\circ}$ & $90^{\circ}$ & $95^{\circ}$ & $1,9^{\circ}$ \\
\hline $\mathrm{API}+\mathrm{INI}{ }^{\wedge} \mathrm{API}-\mathrm{INI}$ & $136,6^{\circ}$ & $125^{\circ}$ & $130^{\circ}$ & $135^{\circ}$ & $1,6^{\circ}$ \\
\hline \multicolumn{6}{|c|}{ Linear Values } \\
\hline$S: N$ & 72,7 & 72,2 & 75,2 & 78,2 & 0 \\
\hline Go:Me & 68,1 & 70,2 & 75,2 & 80,2 & 2,1 \\
\hline Pns-A & 44,1 & 45 & 46 & 47 & 0,9 \\
\hline Sor-Ans & 58,4 & 0 & 0 & 0 & 58,4 \\
\hline Ans-Me & 65,8 & 0 & 0 & 0 & 65,8 \\
\hline Wits & 1 & -2 & 0 & 2 & 0 \\
\hline SN-GoMe & 4,6 & 0 & 0 & 0 & 4,6 \\
\hline Front vertical dimension & $-7,4$ & $-6,6$ & $-5,6$ & $-4,6$ & 0,8 \\
\hline
\end{tabular}

The rotation of the upper right second premolar (180 degrees), as long as lower premolars agenesis, could be related with genetic condition of the patient. To evaluate a possible relation with AGS the importance of odontostomatologic primary care should be encouraged as long as the gathering of case data [8].

Cephalometric analysis of the patient shows main characteristics of the facies, from an orthodontic point of view, if 
possible, interceptive treatment is to be recommended to correct the typical facies growing pattern.

\section{Conclusion}

Literature review doesn't provide any information to exclude correlations between agenesis of dental elements and ALGS so further investigation is needed to permit early diagnosis and the avoidance of complications. This is the first article presenting agenesis in an Alagille patient and more information about AGS oro-facial manifestations is needed in order to increase knowledge in orthodontic treatment and dental management. Early diagnose of agenesis is vital to prevent infra occlusion and ankylosis, this may lead to caries and bone loss in present presenting important medical needs. Cephalometric data's showed discrepancies with standard values, this may lead to early recognition of those patients and also may help to find orthodontic specific protocols and needs.

\section{Summary}

Alagille syndrome (AGS) is a complex multi-systemic genetic disorder which involves primarily liver, heart, eyes, face, and skeletal structure. The major clinical manifestations of AGS are cholestasis, recognizable by bile duct paucity on liver biopsy; cardiac defects, involving the pulmonary arteries; posterior embryo toxon in the eyes; typical facial features; renal and central nervous system abnormalities and butterfly vertebrae. Mortality is approximately $10 \%$, with vascular accidents, cardiac disease, and liver disease accounting for most of the deaths [1]. The facial features associated with Alagille syndrome include a broad forehead, deep-set eyes, up slanting palpebral fissures, prominent ears, bulbous tipped nose, and a pointed chin [13]. The orthodontic and dental features involves maxillary hypoplasia, maxillo-mandibular retrusion, talon cusps. The current study presents dental alterations especially referring to shape and number and facial manifestations of a patient with AGS. A literature review provided no previous data on known patients presenting single or multiple dental agenesis [3].

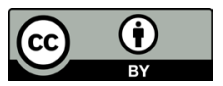

Creative Commons Attribution 4.0

International License

For possible submission use the below is the URL Submit Article

\section{References}

1. Spinner NB, Leonard LD, Krantz ID (2000) Alagille Syndrome. In: Adam MP, Ardinger HH, Pagon RA, et al. (Eds.), GeneReviews ${ }^{\circledR}$, Seattle, USA.

2. Pati GK, Singh A, Nath P, Narayan J, Padhi PK, et al. (2016) A 10-yearold child presenting with syndromic paucity of bile ducts (Alagille syndrome): a case report. J Med Case Rep 10(1): 342.

3. Berniczei-Royko A, Chałas R, Mitura I, Nagy K, Prussak E (2014) Medical and dental management of Alagille syndrome: A review. Med Sci Monit 20: 476-480.

4. Cozzani M, Fontana M (2012) Macrodontic maxillary incisor in alagille syndrome. Dent Res J (Isfahan) 9(Suppl 2): S251-S254.

5. Tsutsumi T, Oguchi H (1991) Labial talon cusp in a child with incontinentia pigmenti achromians: case report. Pediatr Dent 13(4): 236-237.

6. Alagille D, Odievre M, Gautier M, Dommergues JP (1975) Hepatic ductular hypoplasia with characteristic facies, vertebral malformations, retarded physical, mental and sexual development and cardiac murmur. J Pediatr 86(1): 63-71.

7. Spinner NB, Colliton RP, Crosnier C, Krantz ID, Hadchouel M, et al. (2001) Jagged 1 mutations in Alagille syndrome. Hum Mutat 17: 18-33.

8. Farronato G, Garagiola U, Dominici A, Periti G, de Nardi S, et al. (2010) Ten-point 3D cephalometric analysis using low-dosage cone beam computed tomography. Prog Orthod 11(1): 2-12.

9. Cossellu G, Farronato M, Biagi R, Assandri F, Farronato G (2017) Idiopathic hypoplasia of the masseter muscle: A case report. Cranio 35(3): 192-196.

10. Apuzzo DF, Cappabianca S, Ciavarella D, Monsurrò A, Silvestrini-Biavati A, et al. (2013) Biomarkers of periodontal tissue remodeling during orthodontic tooth movement in mice and men: overview and clinical relevance. Scientific World Journal 2013: 105873.

11. Cheng KW, Huang JJ, Wang CH, Chen CL, Jawan B (2004) Anesthetic management of a patient with Alagille's syndrome undergoing living donor liver transplantation without blood transfusion. Chang Gung Med J 27(6): 449-453.

12. Chatterjee M, Mason C (2007) Talon cusps presenting in a child with Alagille's syndrome - A case report. J Clin Pediatr Dent 32(1): 61-63.

13. Bresnahan JJ, Winthrop ZA, Salman R, Majeed S (2016) Alagille syndrome: a case report highlighting dysmorphic facies, chronic illness, and depression. Case Rep Psychiatry 2016: 1657691.

\section{Your subsequent submission with Crimson Publishers will attain the below benefits}

- High-level peer review and editorial services

- Freely accessible online immediately upon publication

- Authors retain the copyright to their work

- Licensing it under a Creative Commons license

- Visibility through different online platforms

- Global attainment for your research

- Article availability in different formats (Pdf, E-pub, Full Text)

- Endless customer service

- Reasonable Membership services

- Reprints availability upon request

- One step article tracking system 